\title{
Effects of upper respiratory tract infections in patients with cystic fibrosis
}

Department of Child Health, Clinical Sciences Building, Leicester University, Leicester LE1 5WW, UK

J Collinson

J Ashman

C O'Callaghan

Department of Microbiology and Immunology, Medical Sciences Building,

Leicester University, Leicester LE1 9HN, UK

K G Nicholson

E Cancio

D C Ireland

V Hammersley

J Kent

Correspondence to Dr K G Nicholson.

Received 11 September 1995

Returned to authors 16 January 1996 Revised version received 23 April 1996 Accepted for publication 13 May 1996

\author{
J Collinson, K G Nicholson, E Cancio, J Ashman, D C Ireland, V Hammersley, \\ J Kent, C O'Callaghan
}

\begin{abstract}
Background - The polymerase chain reaction has improved the detection of picornaviruses and rhinoviruses and our understanding of their role in reversible airways disease. The effects of colds on lower respiratory morbidity and bacterial colonisation in cystic fibrosis remain uncertain.
\end{abstract}

Methods - Children with cystic fibrosis were evaluated regularly in the clinic and the parents notified the investigators when their child developed a cold. Nasopharyngeal specimens were collected at the start of the infection for polymerase chain reaction, bacteriology was also undertaken and again three weeks later, and pulmonary function was measured in children aged $\geq 6$ years at four day intervals for three weeks. The effects of colds on rate of progression of cystic fibrosis were assessed by pulmonary function, Shwachman scores, and radiology.

Results - Thirty eight children suffered 147 colds over 17 months. Picornaviruses were detected in 51 (43\%) of 119 nasopharyngeal specimens, and 21 of the 51 were further identified as rhinoviruses. Pulmonary dysfunction was similar following picornavirus and non-picornavirus infections; the mean change from baseline in forced expiratory volume in one second $\left(\mathrm{FEV}_{1}\right)$ was $-16.5 \%$ and $-10.3 \%$ at $1-4$ days and 21-24 days, respectively, after onset of a cold. Children who experienced more colds than average had evidence of disease progression with reduction in Shwachman score, increasing ChrispinNorman score, and greater deterioration in $F E V_{1}$ per annum. Ten of 12 new bacterial infections were associated with a cold.

Conclusions - Picornavirus and nonpicornavirus colds are associated with pulmonary function abnormalities and disease progression in patients with cystic fibrosis, and predispose to secondary bacterial infection and colonisation.

(Thorax 1996;51:1115-1122)

Keywords: cystic fibrosis, colds, adverse effects.

Bacteria, notably Pseudomonas aeruginosa, are considered the major cause of respiratory morbidity in patients with cystic fibrosis. ${ }^{1}$ Once established in the airways of patients with cystic fibrosis, $P$ aeruginosa initiates inflammation ultimately leading to rèspiratory failure and death. The factors predisposing to airway colonisation with $P$ aeruginosa are unknown but there is increasing evidence that upper respiratory tract infections play a part. A possible synergy between respiratory syncytial virus infection and initial acquisition and chronic colonisation with Pseudomonas has been noted, ${ }^{2}$ and the seasonal increase in the incidence of $P$ aeruginosa paralleled the respiratory virus season in a 25 year retrospective study. ${ }^{3}$ Patients with cystic fibrosis do not have more frequent upper respiratory infections than healthy controls, ${ }^{45}$ but morbidity is evidently greater in cystic fibrosis as respiratory virus infections precede $18-38 \%$ of pulmonary exacerbations. ${ }^{6-8}$

Data concerning the long term effects of viral respiratory infections on disease progression in cystic fibrosis are conflicting. Associations between the annual incidence of viral infection and the rate of decline of clinical and radiological scores, lung function, percentage of ideal weight for height, and frequency and duration of hospitalisation were found in a two year prospective study in Canada. ${ }^{4}$ However, a similar but smaller study in Seattle, USA did not demonstrate any significant adverse effect of respiratory viral infections on pulmonary function. ${ }^{5}$ The Toronto group ${ }^{4}$ found an association between colonisation with $P$ (Burkholderia) cepacia and the incidence of upper respiratory infections. However, no association between viral infections and colonisation was noted in Seattle. ${ }^{5}$ The Canadian workers were unable to isolate viruses from any subject and commented that there may be a relative difficulty in isolating viruses from patients with cystic fibrosis. ${ }^{4}$ Viruses were recovered from similar numbers of patients and siblings in Seattle, but the investigators failed to culture respiratory syncytial virus and parainfluenza viruses. ${ }^{5}$ Most studies of respiratory viruses in cystic fibrosis have employed serology and tissue culture for viral diagnosis. Human rhinoviruses, the major causative agent of the common cold, are fastidious for certain cells and culture conditions and the large number of serotypes precludes serological examination. A number of coxsackie and echo viruses also cause mild respiratory illness. Accordingly, the role of picornaviruses in lower respiratory events in cystic fibrosis is unclear. Semi-nested reverse transcriptase polymerase chain reaction in our laboratory increased by about fivefold the diagnostic yield of picornaviruses in comparison with cell culture. ${ }^{910}$ Using the polymerase chain reaction we and others have shown that picornaviruses, including rhinoviruses, ${ }^{11}$ are frequently associated with ex- 
acerbations of asthma in adults ${ }^{10}$ and children. ${ }^{11}$ The present study was undertaken to investigate the acute effects of picornaviruses and other agents causing upper respiratory infections on pulmonary function in patients with cystic fibrosis, to examine the influence of upper respiratory infections on disease progression, and their relationship with bacterial infection and colonisation.

\section{Methods}

STUDY DESIGN AND PATIENTS

The study was conducted from January 1993 to May 1994 inclusive in patients reviewed at the Leicester Royal Infirmary Cystic Fibrosis Clinic. Forty eight patients aged two months to 18 years (median 7.3 years) were enrolled and $38(79 \%)$ completed the study. One patient died shortly after commencement of the study and in nine cases the families failed to inform the research nurse of respiratory viral illnesses despite frequent reminders. The children who did not participate were of a similar age and sex distribution to those who did. Participants were 19 boys and 19 girls with a median age of 7.5 years (range $0.2-17.2$ years). Twenty four of the 38 were $\geq 6$ years of age and were able to perform pulmonary function tests reliably.

The diagnosis of cystic fibrosis was confirmed in all patients by raised sweat electrolyte concentrations. Parents of children gave written informed consent to the protocol which was approved by the Leicestershire Health $\mathrm{Au}-$ thority ethics committee. Subjects underwent a clinical assessment on enrolment to the study which was repeated at routine clinic visits. The assessment included a clinical history, examination, and measurements of height and weight. Lung function was recorded in children aged $\geq 6$ years and sputum specimens or throat swabs were taken for bacteriological examination at each visit. Children aged $\leq 15$ months were seen in the clinic at monthly intervals and older children every eight weeks. Patients colonised with $P$ aeruginosa were routinely segregated from those without it, and all children were immunised against influenza each autumn. Chest radiographs were taken at the beginning and end of the study and scored using the scheme devised by Chrispin and Nor$\operatorname{man}^{12}$ by a paediatric radiologist who was unaware of the clinical progress of the children. Similarly, Shwachman scores ${ }^{13}$ for each child were calculated at the beginning and end of the study by a member of the cystic fibrosis team who was unaware of the number of upper respiratory infections that each child experienced.

Parents were instructed to contact the investigators as soon as possible after a child with cystic fibrosis developed one or more given features of an upper respiratory infection. A research nurse then examined the child at home within 72 hours of onset of symptoms and collected specimens for bacteriological and virological examination. Nasal swabs were placed high in the anterior nares and a second swab was passed firmly over the pharynx and tonsils.
Swabs in $2.5 \mathrm{ml}$ of virus transport medium were transported to the laboratory on dry ice and stored at $-70^{\circ} \mathrm{C}$. Spirometric tests were performed in children aged $\geq 6$ years during the home visit following the onset of an upper respiratory infection and repeated at four day intervals during the next three weeks. A symptom diary was used by parents to record the presence or absence of respiratory and systemic features during the 10 days after onset of symptoms. Antibiotic therapy and hospital admissions were documented for each child throughout the study.

\section{VIROLOGICAL EXAMINATION}

Respiratory virus infection was established by isolation of virus from nasal or throat swabs or by semi-nested reverse transcriptase polymerase chain reaction. Volumes of $0.2 \mathrm{ml}$ were inoculated onto monolayers of Ohio Hela, MRC-5, C16, Hep2, and MDCK cells. All cell lines were cultured in roller tubes at $33^{\circ} \mathrm{C}$ with $5 \%$ carbon dioxide and examined daily for cytopathological effect. Negative Ohio HeLa cultures were harvested on the seventh day and, after freeze thawing and clarification, were passaged once. Equivocal specimens were passaged up to three times. The remaining cell lines were maintained for up to three weeks. Picornavirus infection was diagnosed after observation of a characteristic cytopathological effect. Inhibition of the cytopathological effect at $37^{\circ} \mathrm{C}$ was not performed routinely but isolation of rhinovirus was confirmed by demonstrating characteristic acid lability at $\mathrm{pH} 3$ and amplification by the polymerase chain reaction.

Polymerase chain reactions for picornaviruses were performed as described previously. ${ }^{9}$ Baseline samples were checked randomly during the study. Cultured rhinoviruses, mostly serotypes 14 and $1 \mathrm{~B}$, were used as positive controls. To detect all picornaviruses a two stage polymerase chain reaction, incorporating a touch-down reaction, was performed on the product of reverse transcription to amplify $380 \mathrm{bp}$, followed by a semi-nested reaction to amplify a sequence of $285 \mathrm{bp} .{ }^{9}$ To detect rhinoviruses $5 \mu \mathrm{l}$ amounts of the primary product were transferred to new tubes and a semi-nested polymerase chain reaction was set up. The product obtained was a band of 202 bp. $^{10}$

\section{BACTERIOLOGICAL EXAMINATION}

Sputum samples or throat swabs from children who were unable to expectorate were obtained from patients during routine clinic visits, at the onset of upper respiratory infections, and three weeks later. Sputum and throat swabs were plated onto chocolate agar, Maconkey agar and Mast UK culture medium, which was used as a selective agar for isolation of $P$ (Burkholderia) cepacia. 


\section{PULMONARY FUNCTION}

Pulmonary function tests in children aged $\geq 6$ years were carried out using the Microloop spirometer system (Micro Medical Ltd, Rochester, UK). The children were trained to perform forced expiratory manoeuvres prior to entry to the study, and pulmonary function tests were performed by a single trained observer who made the measurements between 10.00 and 14.00 hours. The highest value measured at each testing session was recorded throughout the study. Spirometric measurements conformed to American Thoracic Society criteria of acceptability. ${ }^{16}$ The flowvolume loops were uploaded on to a database held on a portable computer, and percentage predicted values of forced expiratory volume in one second $\left(\mathrm{FEV}_{1}\right)$ and forced vital capacity (FVC) were calculated on each occasion according to the height and sex of the child. ${ }^{1718}$ Pulmonary function was measured at four day intervals for three weeks following an upper respiratory infection. Changes in lung function during symptomatic episodes were calculated from the best values taken during clinic visits during the two months preceding the upper respiratory infection when the patients were clinically stable (defined as no recent increase in respiratory symptoms or new physical signs and no upper respiratory tract infection during the previous four weeks).

Children aged $\geq 6$ years underwent extensive pulmonary function testing at intervals of approximately 12 months as part of routine clinical monitoring. Thoracic gas volume, total lung capacity, and residual volume were measured using a whole body plethysmograph (Jaeger $\mathrm{GmbH}$ ) and the ratio of residual volume to total lung capacity was calculated. Maximal mid expiratory flow was measured by a pneumotachograph (Jaeger). To compare measurements over the study period when growth in height and lung size occurred, results were expressed as percentage predicted for height and sex..$^{1920}$ Changes in measurements were expressed as changes over 12 months.

\section{DATA ANALYSIS}

Measurements of baseline $\mathrm{FEV}_{1}$ and FVC were compared with those obtained during each four day epoch by a paired $t$ test. Group mean values - for example, percentage changes in $\mathrm{FEV}_{1}$ in those with and without picornavirus infections - were compared using the unpaired $t$ test. Failure to take into account the fact that some patients had more upper respiratory infections than others may have skewed the results by over-representation of patients with the most frequent infections. Accordingly, the acute changes in $\mathrm{FEV}_{1}$ were also analysed using multilevel modelling which allows for complicated hierarchical correlation structures within the data. ${ }^{21}$ Multilevel modelling was performed using software for Three Level Analysis, ML3 (Institute of Education, University of London, UK).

Unpaired $t$ tests were used to compare the initial Shwachman scores, Chrispin-Norman scores, percentage of subjects' ideal weight for
Table 1 Frequency of symptoms reported during 112 upper respiratory infections and examination findings during 147 infections

\begin{tabular}{lc}
\hline Symptom & Number $(\%)$ \\
\hline Upper respiratory & $104(92.8)$ \\
Runny nose & $74(66.0)$ \\
Clear watery nasal discharge & $68(59.8)$ \\
Sneezing & $59(52.6)$ \\
Stuffy nose & $39(34.8)$ \\
Sore throat & $37(33.0)$ \\
Thick nasal discharge & $25(22.3)$ \\
Red/watery eyes & $13(11.6)$ \\
Hoarseness & $9(8.0)$ \\
Painful swollen neck glands & $7(6.3)$ \\
Face ache or earache & $112(100)$ \\
Total & \\
& \\
Lower respiratory & $65(58.0)$ \\
New cough & $57(50.9)$ \\
Wet cough & $29(25.9)$ \\
Altered sputum & $26(23.2)$ \\
New cough at night & $86(76.0)$ \\
Total & \\
Systemic & $39(34.8)$ \\
Feeling unwell & $7(6.4)$ \\
Muscle aches & $6(5.3)$ \\
Chills & $40(36)$ \\
Total & \\
Clinical findings & $141(96.0)$ \\
Rhinorrhoea & $102(69.4)$ \\
Erythematous throat & $57(38.8)$ \\
Cervical lymphadenopathy & $147(100)$ \\
Total & \\
\hline
\end{tabular}

height, and lung function (expressed as percentage predicted for height and sex) of children with less than or more than 2.7 upper respiratory infections annually. Paired $t$ tests were used to compare these parameters at the beginning and end of the study for children with less than or more than 2.7 upper respiratory infections annually. Like workers in Toronto and Seattle ${ }^{5}$ we used linear regression analysis (with time as the independent variable) of each subject's pulmonary function tests $\left(\mathrm{FEV}_{1}\right.$ and FVC, expressed as a percentage of the predicted value for height and sex) to provide individual annual rates of change in lung function to minimise the effects of random or temporary fluctuations. The regression coefficients of slopes for children with less than or more than the average number of upper respiratory infections per annum were compared by an unpaired $t$ test.

\section{Results}

\section{RESPIRATORY SYMPTOMS}

There were 147 symptomatic upper respiratory infections, giving an annual incidence of 2.7 symptomatic "colds" per child per year (range $1-10 ; 3.4$ per annum in those $<6$ years of age, 2.3 per annum in those $\geq 6$ years; $p=0.04$ ). Table 1 summarises the symptoms recorded in 10 day symptom diaries completed during 112 $(76 \%)$ of the 147 upper respiratory infections. Upper respiratory symptoms were always present and examination revealed rhinorrhoea and pharyngeal inflammation in $141(96 \%)$ and $102(69 \%)$ of the 147 episodes, respectively.

\section{VIROLOGICAL RESULTS}

Diagnostic specimens were available for 119 $(81 \%)$ of the 147 episodes. Picornaviruses were detected by polymerase chain reaction in 51 
Time in 4-day epochs from onset of URTI

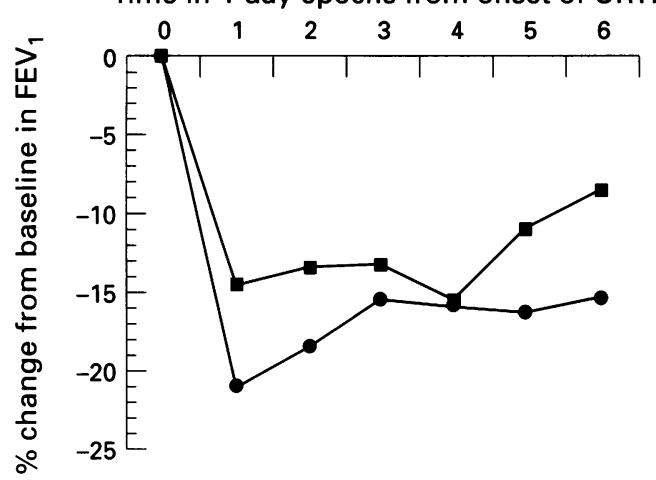

Figure 1 Percentage change from baseline in forced expiratory volume in one second $(F E V)$ during four day epochs from the onset of 15 picornavirus positive (O) and 42 picornavirus negative ( $\left.{ }^{(}\right)$upper respiratory tract infections.

(43\%) of the 119 episodes, of which 21 were identified as rhinoviruses, giving a rhinovirus detection rate of $18 \%$. Four $(8 \%)$ of 48 baseline specimens were picornavirus positive by polymerase chain reaction, three of which were identified as rhinoviruses. Eighty five nasopharyngeal specimens were inoculated onto cell monolayers. Picornavirus cytopathological effect was observed in seven ( $8 \%$ ) samples, only two of which were identified as rhinoviruses on the basis of their acid lability and rhinovirus polymerase chain reaction.

ACUTE EFFECTS OF UPPER RESPIRATORY TRACT INFECTIONS ON PULMONARY FUNCTION IN CHILDREN $\geq 6$ YEARS OF AGE

Comparison of rhinoviruses and other picornaviruses

Twenty four children were $\geq 6$ years of age and were able to perform pulmonary function tests reliably. These 24 children had seven rhinovirus infections and eight infections caused by other picornaviruses. Analysis revealed similar declines in $\mathrm{FEV}_{1}$ and FVC when episodes caused by rhinoviruses and other picornaviruses were compared (data not shown). Accordingly, they were analysed subsequently as a single group.

Comparison of upper respiratory infections positive or negative for picornaviruses Figures 1 and 2 show the mean percentage fall in $\mathrm{FEV}_{1}$ and FVC in 15 and 42 upper respiratory infections that were positive and negative for picornaviruses, respectively. A decline in $\mathrm{FEV}_{1}$ and FVC was detected during the first visit and remained significantly depressed for three weeks. There were no significant differences between the acute pulmonary function abnormalities for upper respiratory infections positive or negative for picornaviruses. For all upper respiratory infections - that is, those positive or negative for picornaviruses - the mean change from baseline in $\mathrm{FEV}_{1}$ was $-16.5 \%$ during days $1-4(\mathrm{p}<0.0005 ; 95 \%$ confidence intervals (CI) $-12.7 \%$ to $-20.3 \%$ ) and $-10.3 \%$ during days $21-24$ ( $<<0.0005 ; 95 \%$ CI $-5.6 \%$ to $-15.0 \%$ ) after onset. Similarly,
Time in 4-day epochs from onset of URTI

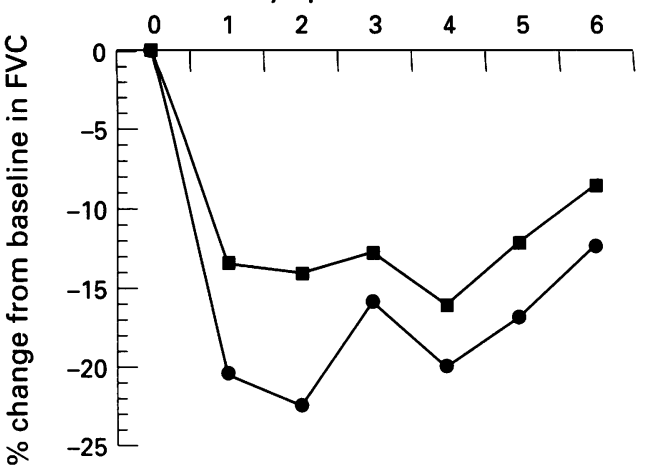

Figure 2 Percentage change from baseline in forced vital capacity (FVC) during four day epochs from the onset of 15 picornavirus positive (O) and 42 picornavirus negative (O) upper respiratory tract infections.

Time in 4-day epochs from onset of URTI

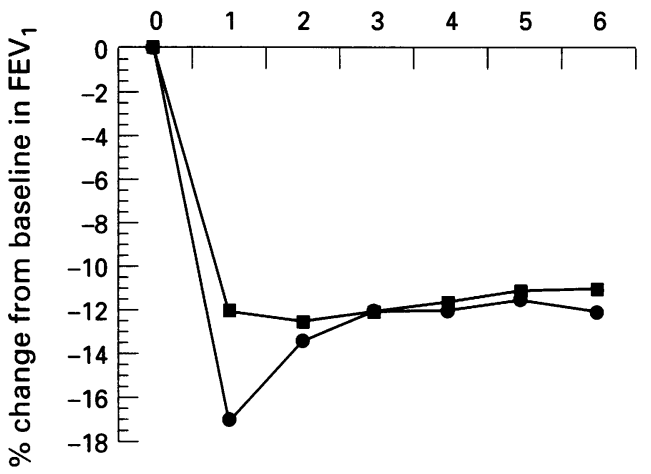

Figure 3 Percentage change from baseline in forced expiratory volume in one second (FEV ) during four day epochs from the onset of 15 picornavirus positive (O) and 42 picornavirus negative (U) upper respiratory tract infections as assessed by ML3 multilevel modelling.

the mean change from baseline FVC was $-15.4 \%$ during days $1-4$ ( $p<0.0005 ; 95 \%$ CI $-11.7 \%$ to $-19.1 \%)$ and $-9.3 \%(\mathrm{p}<0.0005$; $95 \% \mathrm{CI}-4.8 \%$ to $-13.8 \%$ ) during days $21-$ 24. Multilevel modelling analysis (fig 3 ) identified a mean fall in $\mathrm{FEV}_{1}$ of $-11.8 \%(95 \%$ CI $-9.1 \%$ to $-14.6 \%$ ) throughout the three weeks after onset of an upper respiratory infection.

Effects among children with "milder" versus "more severe" initial impairment of FEV Figure 4 shows the mean percentage change in $\mathrm{FEV}_{1}$ from baseline following 18 upper respiratory infections in six children with moderately impaired lung function (defined as baseline $\mathrm{FEV}_{1}$ less than $75 \%$ predicted) compared with 39 upper respiratory infections in 18 children with milder impairment. As shown in fig 4, episodes associated with the more severe initial impairment tended to have greater falls in $\mathrm{FEV}_{1}$, but the differences reached statistical significance during days 5-8 only (mean difference $-9.4 \%, p<0.05)$. Multilevel modelling revealed no significant differences in the decline of $\mathrm{FEV}_{1}$ when upper respiratory infections in children with moderately impaired lung function were compared with those in children with milder impairment. There were no significant differences in the decline of FVC 


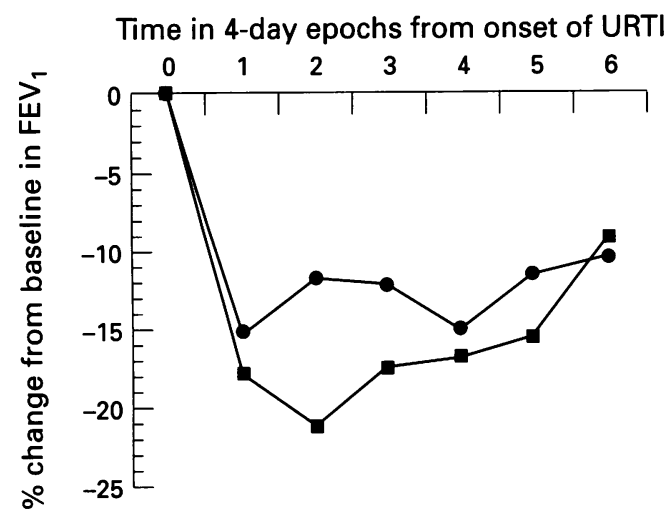

Figure 4 Percentage change from baseline in FEV during four day epochs from the onset of 18 upper respiratory tract infections in six children with baseline $F E V_{1}<75 \%$ (D) and 39 upper respiratory tract infections in 18 children with baseline $F E V_{1} \geq 75 \%$ (O).

Table 2 Mean (SD) initial and follow up characteristics of the 38 participants in the study

\begin{tabular}{|c|c|c|}
\hline Characteristics & $\begin{array}{l}\text { Patients with } \\
<2.7 \text { colds } \\
\text { annually } \\
(n=20)\end{array}$ & $\begin{array}{l}\text { Patients with } \\
>2.7 \text { colds } \\
\text { annually } \\
(n=18)\end{array}$ \\
\hline $\begin{array}{l}\text { Colds/year } \\
\text { Initial }\end{array}$ & $1.8(0.04)$ & $3.8(1.1)^{*}$ \\
\hline $\begin{array}{l}\text { Age (yr) } \\
\text { Shwachman score } \\
\text { Chrispin-Norman score } \\
\text { \% of ideal height for weight }\end{array}$ & $\begin{array}{r}7.9(4.9) \\
86(9.8) \\
6.2(4.9) \\
96.5(5.9)\end{array}$ & $\begin{array}{c}6.8(6.1) \\
86(10.7) \\
5.2(4.9) \\
96.7(12.1)\end{array}$ \\
\hline $\begin{array}{l}\text { Follow up } \\
\text { Change in Shwachman }\end{array}$ & $-1.5(5.2)$ & $-3.3(5.1)^{* *}$ \\
\hline $\begin{array}{l}\text { score/year } \\
\text { Change in } \\
\text { Chrispin-Norman score/year }\end{array}$ & $0.7(1.9)$ & $2.3(3.4)^{* *}$ \\
\hline $\begin{array}{l}\text { Change in \% of ideal height } \\
\text { for weight/year }\end{array}$ & $0.8(2.8)$ & $-1.7(4.7)$ \\
\hline $\begin{array}{l}\text { Median no. of antibiotic } \\
\text { treatments }\end{array}$ & 2.0 & $4.0^{*}$ \\
\hline $\begin{array}{l}\text { Median no. of intravenous } \\
\text { antibiotic treatments }\end{array}$ & 1.0 & 2.0 \\
\hline $\begin{array}{l}\text { Median no. of days of } \\
\text { intravenous antibiotics }\end{array}$ & 12.5 & 28.0 \\
\hline Median no. of days in hospit & 9.5 & 4.5 \\
\hline
\end{tabular}

${ }^{*} \mathrm{p} \leq 0.001$ patients with $<2.7$ infections per year versus those with $>2.7$ infections per year (Mann-Whitney test).

$* * p<0.01$ initial versus follow up scores in patients with $>2.7$ infections per year (Student's $t$ test).

when the two groups were compared, but there was a trend for greater falls in the more severely affected patients.

EFFECT OF UPPER RESPIRATORY INFECTIONS ON PROGRESSION OF DISEASE

Table 2 shows the initial and follow up variables in a group of 20 patients with less than the mean of 2.7 upper respiratory infections per annum and a group of 18 patients with more than 2.7 per annum. There were no significant differences between the initial characteristics of age, Shwachman score, Chrispin-Norman score, or percentage ideal weight for height when the two groups were compared. At follow up there were no significant changes in Shwachman score, Chrispin-Norman score, or percentage ideal weight for height in those with $<2.7$ upper respiratory infections annually (table 2), but among those with more than 2.7 infections annually there were significant changes in Shwachman $(p<0.01)$ and Chris-
Table 3 Mean (SD) initial and follow up results of lung function tests in children aged $\geq 6$ years

\begin{tabular}{|c|c|c|}
\hline Characteristics & $\begin{array}{l}\text { Patients with } \\
<2.7 \text { colds } \\
\text { annually } \\
(n=15)\end{array}$ & $\begin{array}{l}\text { Patients with } \\
>2.7 \text { colds } \\
\text { annually } \\
(n=9)\end{array}$ \\
\hline $\begin{array}{l}\text { Initial } \\
\text { FEV }(\% \text { predicted) } \\
\text { FVC (\% predicted) } \\
\text { TGV (\% predicted) } \\
\% \text { RV/TLC } \\
\text { MMEF (\% } \\
\text { predicted) }\end{array}$ & $\begin{array}{c}86(9.9) \\
89(8.1) \\
108.3(37.4) \\
30.8(6.6) \\
64.7(19.7)\end{array}$ & $\begin{array}{c}80(14.8) \\
87(10.8) \\
120.2(25.2) \\
33.3(11.2) \\
66.7(35.3)\end{array}$ \\
\hline $\begin{array}{l}\text { Follow up } \\
\text { Slope of FEV } \\
\text { versus time (year) } \\
\text { Slope of FVC versus } \\
\text { time (year) } \\
\text { Change in \% } \\
\text { predicted TGV/year } \\
\text { Change in \% RV/ } \\
\text { TLC/year } \\
\text { Change in \% } \\
\text { predicted MMEF/ } \\
\text { year }\end{array}$ & $\begin{array}{r}-0.9(6.7) \\
-1.5(2.1) \\
-3.4(29.1) \\
1.0(7.0) \\
7.4(36.7)\end{array}$ & $\begin{array}{r}-8.4(6.9)^{*} \\
-7.7(8.7) \\
4.8(11.9) \\
4.5(3.5)^{* *} \\
-9.2(10.7)\end{array}$ \\
\hline
\end{tabular}

$\mathrm{FEV}_{1}=$ forced expiratory volume in one second; $\mathrm{FVC}=$ forced vital capacity; $\mathrm{TGV}=$ thoracic gas volume; $\mathrm{RV}=$ residual volume; $M M E F=$ maximal mid expiratory flow.

${ }^{*} \mathrm{p}<0.01 ;{ }^{* *} \mathrm{p}<0.05$ for initial versus follow up scores (Student's $t$ test)

pin-Norman scores $(p=0.01)$, but not in percentage ideal weight for height.

Table 3 shows the initial and follow up pulmonary function variables of the children aged $\geq 6$ years. Measurements of thoracic gas volume, the ratio of residual volume to total lung capacity, and maximal mid expiratory flow, expressed as a percentage of predicted for height, were completed in 20 of the 24 children. There were no significant differences between the initial measurements of pulmonary function of the two groups. To identify a potential cumulative effect of upper respiratory tract infections on the progression of cystic fibrosis pulmonary disease (and to decrease the influence from an upper respiratory infection shortly before termination of the study), the annual rates of deterioration of $F E V_{1}$ and FVC were derived by linear regression. Table 3 shows that there was a significant decrease in $\mathrm{FEV}_{1}$ in the group with the more frequent infections compared with those with less than the average number $(p<0.01)$. The steeper slope in this group reflects a mean change in $\mathrm{FEV}_{1}$ of $-8.4 \%$ from a mean $\mathrm{FEV}_{1}$ of $80 \%$ predicted to a mean of about $72 \%$ predicted. The slope of change of FVC per annum tended to be greater $(p=0.07)$ in the cohort with the more frequent upper respiratory infections. Here the slope reflects a mean change in FVC of $-7.7 \%$ from a mean of $87 \%$ predicted to a mean of about $79 \%$ predicted.

No significant differences between the initial measurements of thoracic gas volume, ratio of residual volume to total lung capacity, and maximal mid expiratory flow expressed as percentage predicted for height were detected when the two groups were compared (table 3). At follow up, measurements of thoracic gas volume, ratio of residual volume to total lung capacity, and maximal mid expiratory flow in those with $<2.7$ infections annually revealed no significant changes from the initial results. Among those with $>2.7$ upper respiratory infections annually, the annual change of the 
ratio of residual volume to total lung capacity was of borderline statistical significance $(\mathrm{p}=$ $0.05)$.

The group with $>2.7$ upper respiratory infections annually received more oral and intravenous antibiotic treatments than the group with fewer infections $(p<0.001)$, but there were no significant differences between the two groups in the number of intravenous treatments, number of days of intravenous therapy, or days in hospital.

\section{BACTERIAL COLONISATION}

Twelve of the 38 children experienced 12 new infections with $P$ aeruginosa, $P$ (Burkholderia) cepacia, Haemophilus influenzae or Staphylococcus aureus during the study. Five new bacterial infections occurred in the 18 children with $>2.7$ upper respiratory infections per annum and seven occurred in the 20 children with fewer upper respiratory infections. New pseudomonas infections occurred in three of the seven non-colonised children in the group with $>2.7$ upper respiratory infections annually and in three of five non-colonised children with fewer upper respiratory infections per annum. Thus, there was no significant difference in the rate of acquisition of new bacteria in the two groups.

Overall, 121 bacteriological specimens were collected from the 12 children experiencing new infections until, and including, the positive specimen. Ten of 46 specimens collected from the 12 children during the symptomatic stage of upper respiratory infections and three weeks later were positive for the first time for $P$ aeruginosa, $P$ (Burkholderia) cepacia, Haemophilus influenzae or Staphylococcus aureus. In contrast, only two of 75 specimens collected during routine visits to these 12 children were positive for one of these pathogens for the first time $\left(\chi^{2}\right.$ with continuity correction $=9.57 ; \mathrm{p} \leq 0.01)$. Sputum samples and throat swabs from 27 of the $38(71 \%)$ children were positive for $P$ aeruginos a prior to enrolment. Of the 11 without previous $P$ aeruginosa infection, six acquired the organism during the study for the first time. Five of the six isolations were made during the symptomatic phase of an upper respiratory infection or three weeks thereafter; a picornavirus was identified for three of these five colds. Sputum samples and throat swabs from three of the six children became persistently infected after the upper respiratory infection and two others had a further isolation of $P$ aeruginosa after a further cold. Only one of the six new infections with $P$ aeruginosa was identified during an asymptomatic period. One child who was colonised with $P$ aeruginosa previously became persistently infected with $P$ (Burkholderia) cepacia within three weeks of an upper respiratory infection. Similarly, Haemophilus influenzae was recovered for the first time from three children within three weeks of an upper respiratory infection, and one new Staphylococcus aureus infection also occurred following a picornavirus infection. One child had $H$ influenzae recovered from a respiratory sample taken during an asymptomatic period.

\section{Discussion}

This study has focused on the short and longer term effects of upper respiratory infections in young patients with cystic fibrosis. Our cohort had a median enrolment age of 7.5 years and were younger than those studied in Toronto ${ }^{4}$ and Seattle. ${ }^{5}$ In our study children aged $<6$ years had an annual incidence of 3.4 colds whereas older children had a mean of 2.3 per annum. The frequency of viral upper respiratory tract infections is not significantly different between patients with cystic fibrosis and their siblings ${ }^{45}$ and the age related rates in our study are in accord with those in normal children. ${ }^{22}$ Rhinorrhoea, confirmed by clinical examination, occurred in more than $90 \%$ of episodes; the clinical features and virological findings suggest that an upper respiratory infection was the primary event.

In this study 30 of 51 (59\%) specimens positive by picornavirus polymerase chain reaction were not identified as rhinoviruses. Similarly, 63 of 147 (43\%) specimens from asthmatic children in Southampton that were positive by picornavirus polymerase chain reaction were not identified as rhinoviruses. ${ }^{11}$ These observations suggest that picornaviruses that were not identified as rhinoviruses may have been coxsackie or echoviruses that are associated with mild respiratory tract illness. Conceivably, some of the viruses in the current study were rhinoviruses not recognised by the rhinovirus secondary PCR primer. However, our polymerase chain reactions for rhinoviruses and picornaviruses were previously validated using RNA from 48 rhinoviruses and 12 other picornaviruses of known serotype. ${ }^{9}$ Moreover, in the present study only two of the seven nasopharyngeal specimens that gave a typical picornavirus cytopathological effect were further identified as rhinoviruses by acid lability and polymerase chain reaction - that is, less than half of the isolates had the rhinovirus property of acid lability.

As reported by other workers, ${ }^{23}$ upper respiratory infections were commonly associated with lower respiratory symptoms. Despite differences in age and baseline pulmonary function, both the previous ${ }^{23}$ and current studies demonstrated significant decreases in airflow persisting for at least three weeks after onset of an upper respiratory infection, which were far greater than those seen in normal children of comparable age with colds. ${ }^{24}$ Hordvik et $a l^{23}$ noted no difference between the decline in peak expiratory flow rate in 10 confirmed cases of influenza in comparison with 25 other upper respiratory infections. We found similar pulmonary function abnormalities in seven cases of rhinovirus and eight other picornavirus infections, and in 57 colds positive or negative for picornaviruses. In light of these observations and the finding in asthmatic adults ${ }^{10}$ and children $^{11}$ that rhinoviruses, coronaviruses OC43 and $229 \mathrm{E}$, influenza $\mathrm{B}$, respiratory syncytial virus, parainfluenza viruses and chlamydia are all associated with reduction in peak expiratory flow, we postulate that most, if not all, respiratory viruses can adversely affect pulmonary function in cystic fibrosis. 
To examine the role of colds in the progression of cystic fibrosis we divided the 38 patients into two groups - one group of 20 with less than the average of 2.7 colds per year, and 18 with a higher rate. At follow up, children with $>2.7$ colds annually had evidence of disease progression with reduction in Shwachman and increasing Chrispin-Norman scores, whereas those with fewer infections per annum did not deteriorate; neither group suffered a deterioration in percentage ideal weight for height. In the children over six years of age in whom pulmonary function was measured, those with $>2.7$ colds annually had a modest increase in the ratio of residual volume to total lung capacity per annum, but there were no changes in thoracic gas volume or maximal mid expiratory flow. However, the group with $>2.7$ colds per annum had significantly faster rates of decline of $\mathrm{FEV}_{1}$. The slope of the regression line for FVC in those with $>2.7$ colds annually was -7.7 which represents a non-significant $(p=0.07)$ trend for decline over time.

The findings in the present study of a greater rate of disease progression in the high infection rate group, as assessed by clinical and radiological scores and decline in pulmonary function, are in accord with observations in Toronto ${ }^{4}$ and Liverpool, UK, ${ }^{25}$ but differ from those in Seattle. ${ }^{5}$ Interestingly, the annual rates of decline in Shwachman score and pulmonary function in the high infection rate group in the present study were approximately half those observed in Toronto. ${ }^{4}$ Our patients had fewer colds per annum than those in the Toronto study, ${ }^{4}$ but the frequency of colds in children with cystic fibrosis in the Seattle study is unclear. ${ }^{5}$ More patients ( $71 \%$ ) in the present study were colonised with $P$ aeruginosa than in the Seattle study $(42 \%)$, but the proportion colonised with $P$ aeruginosa in the Toronto study is unknown. ${ }^{4}$ Conceivably, the different findings in these studies are related to differences in the number of colds, bacterial colonisation with $P$ aeruginosa, or possibly an interaction between the two. ${ }^{2}$ The differences might also be related to the study size, since conclusions on disease progression in the Seattle study ${ }^{5}$ were made on groups of only six and nine children.

In the present study newly acquired respiratory infection with $P$ aeruginosa, $P$ (Burkholderia) cepacia, $H$ influenzae, and $S$ aureus was strongly associated with upper respiratory infections. An association between colonisation with $P$ (Burkholderia) cepacia and the incidence of viral infections was also noted in the Toronto study. ${ }^{4}$ Many reports refer to common upper respiratory tract infections acting as co-factors for bacterial infections. ${ }^{26-29}$ In this study there were no significant differences in the rate of acquisition of new bacterial pathogens in the groups with $>2.7$ or $<2.7$ upper respiratory infections per annum. This may be partly due to the increased use of antibiotics in the group with the higher infection rate. The deterioration in lung function and clinical and radiological scores associated with frequent acute viral infections may be a direct consequence of the viral infection. Irrespective of the mechanism, our findings indicate upper respiratory infections to be of great importance in the progression of cystic fibrosis.

In conclusion, we have shown that picornavirus and non-picornavirus colds in patients with cystic fibrosis are associated with acute pulmonary function abnormalities which persist for three weeks, increased rate of disease progression, and a predisposition to pulmonary bacterial infection. Our findings emphasise the need for annual influenza vaccination and the development of effective prophylaxis against other respiratory viruses. A reduction in exposure to people with colds may be beneficial, but respiratory viruses are ubiquitous, shedding can occur for several weeks after onset of colds, and transmission by fomites is considered an important means of transmission.

We gratefully acknowledge the support of the Cystic Fibrosis Trust and the assistance of Lucy Wilde, Paul Lambert, and Dr Caroline Beardsmore. We also thank the study participants and their parents without whom this work would not have been possible.

1 Høiby N. Microbiology of lung infections in cystic fibrosis patients. Acta Paediatr Scand 1982;Suppl 301:33-54.

2 Petersen NT, Høiby N, Mordhurst CH, Lind K, Flensborg $\mathrm{EW}$, Brunn B. Respiratory infections in cystic fibrosis patients caused by virus, chlamydia and mycoplasma patients caused by virus, chlamydia and mycoplasma possible synergism with Pseudo
Paediatr Scand 1987;76:955-61.

3 Johansen HK, Høiby N. Seasonal variation in Pseudomonas colonisation in Danish patients with cystic fibrosis over 25 years. Thorax 1992;47:109-11.

4 Wang EEL, Prober CG, Manson B, Corey M, Levison H. Association of respiratory viral infections with pulmonary deterioration in patients with cystic fibrosis. $N \mathrm{Engl} f \mathrm{Med}$ 1984;311:1635-8.

5 Ramsey BW, Gore EJ, Smith AL, Cooney MK, Redding GJ, Foy $\mathrm{H}$. The effects of respiratory viral infections on patients with cystic fibrosis. Am $\mathcal{F}$ Dis Child 1989;143: patients

6 Wright PF, Khaw KT, Oxman MN, Shwachman H. Evaluation of the safety of amantadine- $\mathrm{HCl}$ and the role of respiratory viral infections in children with cystic fibrosis. $\mathcal{F}$ Infect Dis 1976;134:144-9.

7 Pribble CG, Black PG, Bosso JA, Turner RB. Clinical manifestations of cystic fibrosis associated with non bacterial infections. $\mathcal{F}$ Pediatr 1990;117:200-4.

8 Ong ELC, Ellis ME, Webb AK, Neal KR, Dodd M, Caul $\mathrm{EO}$, et al. Infective respiratory exacerbations in young adults with cystic fibrosis: role of viruses and atypical micro-organisms. Thorax 1989;44:739-40.

9 Ireland DC, Kent J, Nicholson KG. Improved detection of rhinoviruses in nasal and throat swabs by semi-nested RTPCR. $\mathcal{F}$ Med Virol 1993;40:96-101.

10 Nicholson KG, Kent J, Ireland DC. Respiratory viruses and exacerbations of asthma in adults. BMF 1993;307:982-5.

11 Johnston SL, Pattemore PK, Sanderson G, Smith S, Lampe $\mathrm{F}$, Josephs L, et al. Community study of role of viral infections in exacerbations of asthma in 9-11 year old children. BMF 1995;310:1225-8.

12 Chrispin AR, Norman AP. The systematic evaluation of the chest radiograph in cystic fibrosis. Pediatr Radiol 1972;2: 101-6.

13 Shwachman H, Kulczycki LL. Long term study of one hundred and five patients with cystic fibrosis. Am $\mathcal{F}$ Dis Child 1958;96:6-15.

14 Chomczynsky P, Sacchi N. Single step method of RNA isolation by acid guanidium thiocyanate-phenol-chloroform extraction. Anal Biochem 1987;162:156-9.

15 Bruce CB, Al-Nakib W, Almond JW, Tyrrell DAJ. Use of synthetic oligonucleotide probes to detect rhinovirus RNA. Arch Virol 1989;105:179-87.

16 Renzetti AD. Snowbird workshop in standardisation of spirometry: American Thoracic Society. Am Rev Respir Dis 1979;119:831-8.

17 Solymar L, Aronssen PM, Bake B, Bjure J. Nitrogen single breath test, flow volume curves and spirometry in healthy children, 7-18 years of age. Eur $\mathcal{F}$ Respir Dis 1980;61: 275-86.

18 Cogswell JJ, Hull D, Milner AD, Norman AP, Taylor B. Lung function in children. I. The forced expiratory volumes in healthy children using spirometer and reverse plethysmograph. Br 7 Dis Chest 1975;60:40-50.

19 Zapletal A, Paul T, Samenek M. Pulmonary elasticity in children and adolescents. $\mathcal{F}$ Appl Physiol 1976;40:953-61.

20 Zapletal A, Paul T, Samenek M. Die Bedeutung heutiger Methoden der Lungenfunktionsdiagnostik zur Festellung einer Obstruktion der Atemweger bei Kindern und Jueiner Obstruktion der Atemweger bei Kinde

21 Goldstein H. Multilevel mixed linear model analysis using iterative generalised least squares. Biometrika 1986;73: 43-56. 
22 Monto AS, Sullivan KM. Acute respiratory illness in the community. Frequency of illness and the agents involved. Epidemiol Infect 1993;110:145-60.

23 Hordvik NL, Konig P, Hamory B, Copperstock M, Kreutz $\mathrm{C}$, Gayer D, et al. Effects of acute viral respiratory tract infections on patients with cystic fibrosis. Pediatr Pulmonol 1989;7:217-22.

24 Collier AM, Pimmel RL, Hasselblad V, Clyde WA, Knelson $\mathrm{JH}$, Brooks JG. Spirometric changes in normal children with upper respiratory infections. Am Rev Respir Dis 1978; 117:47-53.

25 Smyth AR, Smyth RL, Tong CYW, Hart CA, Heaf DP. Effect of respiratory virus infections including rhinovirus on clinical status in cystic fibrosis. Arch Dis Child 1995; 73:117-20.

26 Loosli CG. Influenza and the interaction of viruses and bacteria in the respiratory tract. Medicine 1973;52:369-84. 27 Cartwright KAV, Jones DM, Smith AJ, Stewart JM, Kaczmarski EB, Palmer SR. Influenza $\mathrm{A}$ and meningococcal disease. Lancet 1991;338:554-7.

28 Berman S. Epidemiology of acute respiratory infections in children in developing countries. Rev Infect Dis 1991;13 (Suppl 6):S454-62

29 Korppi M, Heiskanen-Kosma T, Jalonen E, et al. Aetiology of community-acquired pneumonia in children treated in hospital. Eur F Pediatr 1993;152:24-30. 